Acta Poetica 29-1

PRIMAVERA

2008

\title{
Preceptos viejos / modelos nuevos
}

\author{
Bulmaro Reyes Coria
}

En todo discurso, la tarea fundamental del orador es adecuar el lenguaje al género, al tema y a la condición de los oyentes; en esto consiste el decoro, que no puede definirse fácilmente. El decoro debe buscarse en la interrelación entre las personas que hablan y las que escuchan: emisores y receptores. Este ensayo divide a los emisores y a los receptores en cinco clases, de acuerdo con su actitud ante el acto del habla: naturales, eruditos, eruditos a la violeta, pseudoeruditos y engreídos. Para que el emisor encuentre el decoro, ha de ver cuatro cosas: qué diga, en qué lugar, de qué modo, a qué receptor. Sólo los emisores engreídos logran cabalmente el decoro y nos enseñan a comunicarnos efectivamente.

In every discourse, the main goal of the orator is decorum; this concept, that can not be easily defined, consists in fitting language to genre, theme, and capacity of the listener. It has to be looked after in the interaction in between the speaker and the listener: emisor and receiver. This essay divides both, emisor and receiver, into five different classes, depending on its attitude towards the act of speech: natural, erudite, superficial erudite, pseudo-erudite, and conceited. To find decorum, the emisor has to consider the following: what is being said, where, in what manner, and to whom. Only a conceited emisor achieves finished decorum, and can teach us to communicate effectively

Palabras clave: retórica, comunicación, decoro, emisor, receptor 

Acta Poetica 29-1

PRIMAVERA

2008

Bulmaro Reyes Coria

Preceptos viejos / modelos nuevos

I. En el Orador perfecto, de Marco Tulio, se sostiene que lo más difícil para quienes viven de la palabra hablada o escrita es adecuar el lenguaje al género, al tema y a la condición de los oyentes, es decir, al decoro de la oración, a lo conveniente, y que ignorar esto lleva a los hombres a cometer errores en el discurso, el cotidiano o el preparado; en la poesía, y aun en la vida misma. Dice el romano:

Como en la vida, así en la oración, nada es más difícil que ver qué sea decoroso. A esto los griegos lo llaman prépon; nosotros digámosle cuerdamente decoro... por la ignorancia de éste se peca no sólo en la vida sino muy a menudo en los poemas y en la oración. ${ }^{1}$

¿Dónde o cómo encontrar el decoro del habla, ya sea escrita o entonada? Quien habla o escribe debe conocer la fortuna, el honor, la autoridad, la edad, la época, el lugar, el tiempo, en fin, a los distintos interlocutores y todas sus circunstancias, y tratar a cada uno y cada una de éstas con distinto género de palabras y de sentimientos. En todo discurso y en todas sus

${ }^{1}$ Cic., Or., 70: Vt enim in vita sic in oratione nihil est difficilius quam quid deceat videre. Прє́лоv appellant hoc Graeci, nos dicamus sane decorum... huius ignoratione non modo in vita sed saepissime et in poematis et in oratione peccatur. 
partes, siempre hay que pensar qué es conveniente y qué no lo es. Ésta es la explicación de Cicerón:

Empero, qué sea decoroso ha de verse por el orador no sólo en las sentencias sino también en las palabras, pues no toda fortuna, no todo honor, no toda autoridad, no toda edad, ni en verdad todo lugar o tiempo u oyente, ha de ser tratado con el mismo género o de palabras o de sentencias, y siempre ha de considerarse qué es decoroso en toda parte de la oración, como de la vida; lo cual está puesto en la cosa acerca de la cual se trata, y en las personas de los que dicen y de los que oyen. ${ }^{2}$

Eso, lo conveniente, lo decoroso, es invisible y no fácilmente definible, y se encuentra en la interrelación de las personas que hablan y de las que escuchan. Para los filósofos moralistas y sus oyentes temerosos, éste sería uno de sus deberes, "lo bueno o lo malo"; para los gramáticos y sus oyentes educandos, "lo correcto o lo incorrecto"; para los oradores y sus oyentes expectantes, "lo persuasivo o lo no persuasivo". Como mínimo esclarecimiento, del Orador perfecto se adivina que sería ridículo o inconveniente o acaso incomprensible para el correspondiente interlocutor, que tratándose, por ejemplo, de goteras, alguien pidiera de modo poético su reparación, o, en otro sentido, que si se hablara de la grandeza de los pueblos, esto se hiciera con humildad y modestia. Dice Cicerón al respecto:

¡Pues cuán indecoroso es usar de amplísimas palabras y de lugares comunes, cuando dices ante un único juez acerca de go-

\footnotetext{
${ }^{2}$ Cic., Or., 71: Est autem quid deceat oratori videndum non in sententiis solum sed etiam in verbis. Non enim omnis fortuna, non omnis honos, non omnis auctoritas, non omnis aetas nec vero locus aut tempus aut auditor omnis eodem aut verborum genere tractandus est aut sententiarum, semperque in omni parte orationis ut vitae quid deceat est considerandum; quod et in re, de qua agitur, positum est, et in personis et eorum qui dicunt et eorum qui audiunt.
} 
teras; y sumisa y sutilmente, acerca de la majestad del pueblo romano! $!^{3}$

El poeta, o creador, es sujeto de error, si pone palabras de sabio en boca de tontos o facinerosos, ${ }^{4} \mathrm{o}$ si pretende poder expresarlo todo. Con frecuencia habría que guardar silencio. Recordemos, para el caso, el histórico cuadro de la Inmolación de Ifigenia, que hiciera el pintor griego Timantes. Ifigenia, hija de Clitemnestra y Agamemnón, y hermana de Electra y Orestes, debía ser sacrificada por su propio padre, para aplacar los vientos contrarios que impedían la salida de las naves hacia Troya. Agamemnón obedeció el mandato divino que le había trasmitido el adivino Calcas; pero, cuando iba a consumar el sacrificio, la misma Artemis sustituyó a Ifigenia por una cervatilla, y la transportó desde aquel puerto de Aulis hasta la región de Tauro, donde la constituyó en sacerdotisa de su templo. En el cuadro a que me refiero, el creador Timantes reproduce triste al adivino Calcas; más triste, a Ulises; apesadumbrado, a Menelao; pero a Agamemnón, para evitar el error, lo pinta con la cabeza velada, porque no había pincel humano que pudiera imitar el dolor que reflejaba el rostro de aquel que fuera padre de la víctima, y su verdugo a la vez.

II. Poner límites a la jurisdicción de lo bueno y lo malo, de lo correcto y lo incorrecto, o de lo persuasivo y lo no persuasivo, no es cosa fácil. En este problema intervienen al menos tres factores, por demás trillados: emisor, mensaje y receptor. Todos sabemos que es tarea del emisor emitir mensajes, y del receptor, recibirlos; pero, como también intuimos que estas funciones no siempre se cumplen, o no siempre correctamen-

\footnotetext{
${ }^{3}$ Cic., Or., 72: Quam enim indecorum est, de stillicidiis cum apud unum iudicem dicas, amplissimis verbis et locis uti communibus, de maiestate populi Romani summisse et subtiliter!

${ }^{4} \mathrm{Cic}$., Or., 74: poeta... peccat etiam, cum probi orationem adfingit improbo stultove sapientis.
} 
te, me parece oportuno dividir en clases al emisor y al receptor, con la finalidad de encontrar alguna explicación. Divido a los emisores y a los receptores en cinco clases, de acuerdo con su actitud ante el acto del habla: naturales, eruditos, eruditos a la violeta, pseudoeruditos y engreídos. A continuación defino a los emisores; la definición de cada uno de los receptores corresponde exactamente a la de los emisores.

1. El emisor NATURAL no tiene pulimento, no se ajusta a reglas de arte (en este caso, de gramática), y no sabe que habla mediante enunciados. Por lo tanto, no se cuestiona si la comunicación se cumple o no, aunque comúnmente ésta se cumple en la realidad. Se podrían citar, como ejemplo, los siguientes mensajes:

A. Chiiiiiiicles, chiiiiiiicles, lleeeve sus chiiicles.

Este mensaje cumple su función comunicativa, independientemente de que los posibles clientes la acepten o no.

B. ¡Se hizo chica la pelea! ¡Pierde la grande!... ;Aaa-bran las puertas....15

En el palenque, el mensaje cumple su función comunicativa, sea que agradara o no a quienes hubieran apostado al gallo perdedor.

2. El emisor ERUDITO (que alguna vez fue "natural") es instruido en varias ciencias y acaso en el arte de la gramática. Sabe lo que es un enunciado, o puede fácilmente entenderlo. Por lo tanto, se cuestiona a sí mismo si su comunicación es correcta o no, y ésta puede cumplirse o no en la realidad. Veamos algunos ejemplos:

\footnotetext{
${ }^{5}$ Esta misma fórmula jergal la pone Juan Rulfo en boca de Dionisio Pinzón ( $E l$ gallo de oro, en Juan Rulfo, Imagen y obra escogida, México, UNAM, 1984, p. 45). En tal caso, también cumple su función comunicativa con los lectores, aunque no mueva a quienes nunca hayan estado en un palenque.
} 
C. El sentido del morfema de anterioridad parece penetrar en la esfera de lo que denotan los morfemas de perspectiva de pretérito, al menos en ciertas ocasiones. ${ }^{6}$

Este mensaje cumple su función comunicativa, aunque solamente entre pares, dado que siempre habrá quienes jamás logren explicar esto, y quienes nunca lo entiendan.

D. Si se cambia el signo a un número par de factores, el signo del producto no varía. ${ }^{7}$

El mensaje cumple su función comunicativa, independientemente de que haya profesores que jamás logren explicar esto, y alumnos que nunca lo entiendan.

3. El emisor ERUDITO A LA VIOLETA sólo tiene una tintura superficial de gramática. Ignora lo que a ciencia cierta es un enunciado, y no sabe qué hacer para que la comunicación se cumpla, y ésta puede cumplirse o no en la realidad. He aquí algunos ejemplos:

\section{E. No actuó a tiempo para evitar la catástrofe humanitaria. ${ }^{8}$}

El mensaje cumple su función comunicativa, aunque haya profesores obsesionados, que en clase de redacción darían seis de calificación al autor de esa nota, sin duda, tan solo para desprestigiarlo.

F. ... luego de que los gastos originados por el accidente en que un helicóptero se desplomó al ser agredido por delincuentes que habían asaltado un banco. ${ }^{9}$

${ }^{6}$ Tomado de Emilio Alarcos Llorach, Gramática de la lengua española, Madrid, Espasa Calpe, 1999 (1994), p. 165.

${ }^{7}$ Tomado de A. Baldor, Álgebra, México, Publicaciones Cultural, 1993, p. 77.

${ }^{8}$ Portada, a cuatro columnas, de El Universal, sección Internacional, 12 de noviembre de 1996. Cabe recordar que humanitario - "que mira o se refiere al bien del género humano; benigno, caritativo, benéfico" - no es atribución de catástrofe.

${ }^{9}$ Reforma, sección Ciudad y Metrópoli, 23 de agosto de 1997, p. 1, primera columna. 
Este mensaje no cumple su función comunicativa, sea que la noticia agrade o no a sus lectores, pues ninguno de ellos podrá saber lo que ocurrió con los gastos originados: si fueron cubiertos por el seguro o no, si se pagaron, si se cobraron, etcétera. Este fenómeno se conoce como anacoluto.

4. El emisor PSEUDOERUDITO presume de conocimientos gramaticales, pero en realidad es un absoluto ignorante en ese campo. Siempre asume que la comunicación se cumple, pero ésta puede cumplirse o no en la realidad. Para dar ejemplos de este emisor es necesario pasar de lo auditivo a lo visual, o mostrar algunos textos llenos de lo que comúnmente llamamos errores: el mal acento, las equivocadas zeta o ce, be o ve, o el barbarismo, o la incorrecta concordancia, así como la incorrecta puntuación. Creo que no es conveniente citar ejemplos.

5. El emisor ENGREÍDO está encariñado con la gramática, y su producción hace obvio que la domina. Es persona culta que ostenta sus enunciados, y piensa que todos debemos entender su comunicación, la cual puede cumplirse o no en la realidad. Veamos ejemplos:

G. Abro luego las manos, quedas libre. $Y$ el corazón te grita que te quedes. ${ }^{10}$

H. El mar se mide por olas, el cielo por alas, nosotros por lágrimas. ${ }^{11}$

En el siguiente esquema pueden verse algunas relaciones de comunicación debidas a diferencias que se dan de acuerdo con los tipos de emisor y de receptor.

\footnotetext{
${ }^{10}$ Rubén Bonifaz Nuño, Tres poemas de antes.

${ }^{11}$ Jaime Sabines, Horal.
} 


\section{EMISOR}

\section{RECEPTOR}

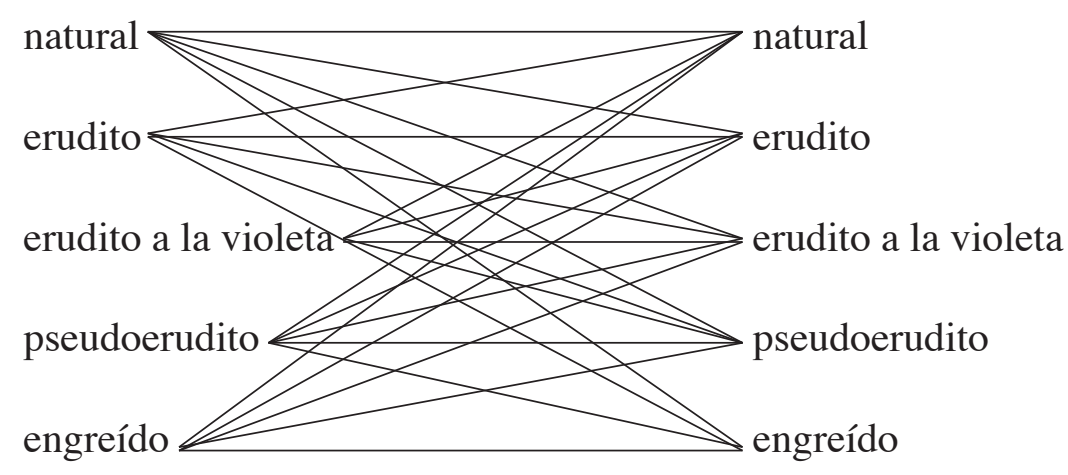

III. Si consideramos que cualquiera de los cinco emisores puede dirigirse a cualquiera de los cinco receptores, encontraremos que se generan al menos veinticinco modalidades de comunicación, y que tiene que haber mínimamente cuarenta formas de adaptación: veinte, de emisor a receptor, y veinte, viceversa.

Para explicar mejor lo que digo, cito aquí lo que en cierta ocasión me decía el padre de mis ahijados:

I. Compadre, cuando hablo contigo lo hago de manera natural, pero en la chamba le tengo que bajar al verbo porque si no se ríen de mí o no me entienden.

Pienso que se da comunicación llana entre iguales, pero en cuanto el emisor y el receptor son de diferente clase, a veces de manera natural, a veces artificial, se dan acoplamientos, aunque éstos sean mínimos.

Cuando hace cuarenta años iba a mi pueblo el padre Roberto Martínez - vaya su nombre en homenaje-, en el templo 
no cabía la gente, pues pronunciaba unos sermones dominicales que de veras hacían llorar, aunque luego nadie supiera bien a bien lo que el sagrado orador había querido decir.

Con frecuencia, a los emisores les sobran palabras y pensamientos, y, más que información, los receptores, ansiando huir de un mundo que pretende manipularlos, se sienten satisfechos por tanto ruido que, curiosamente, les permite la fuga. Así, aquéllos se desahogan; éstos se pierden. Mucha televisión, mucha lectura, mucha prensa, y poca o nula modificación positiva de conducta.

Desde otra perspectiva, los emisores pueden ser escritores, oradores, locutores, comentaristas de radio, televisión o prensa, profesores en sus distintas manifestaciones. Los receptores pueden ser estudiantes, desempleados, jubilados, ociosos, enfadados, uno que otro interesado. En determinados momentos, los emisores pasan a ser receptores, y viceversa, y otra vez viceversa de modo contingente.

Los emisores conscientes de sus emisiones quieren ser aprobados, y así consideran la voluntad de los receptores, que escuchan o leen o miran. Se adaptan a su arbitrio y capricho. En el antiguo mundo, por ejemplo, decía Cicerón, los habitantes de Caria, Frigia y Misia, ciudades de Asia Menor, no eran de ningún modo de orejas pulidas o de sensibilidad elegante; les gustaba la abundancia, lo grosero. En cambio, los rodios eran más finos, más moderados. Sin embargo, en comparación con éstos, los atenienses amaban especialmente lo elegante, lo prudente, lo sincero, lo limpio. De este modo, han llegado hasta nosotros tres géneros de discurso, que reciben precisamente esos nombres: a) el género asiático, el cual es muy rebuscado y 
abundante; b) el rodio, moderado y no tan largo, y c) el ático, claro y castizo. ${ }^{12}$

De este modo, como las antiguas reglas de la composición mandan al emisor acomodarse a los sentidos del receptor, un orador ático que hable a un público ático lo hará de manera natural; pero, si sus oyentes son asiáticos o rodios, el ático deberá adaptarse a ellos. En palabras de aquel compadre mío, habrá de "bajarle" a su cultura. Y así respectivamente: un asiático tendrá que pulirse para arengar a un ático, y un rodio, exagerar para agradar a los frigios. Para unos, hay que ser humildes; para otros, elegantes y sobrios. En las bellas artes, a unos deleita lo hórrido, lo inculto, lo escondido y lo opaco; a otros, lo nítido, lo alegre, lo iluminado. ${ }^{13}$

Así, cuatro cosas ha de ver el emisor: qué diga, en qué lugar, de qué modo, a qué receptor.

El emisor natural tiene pocas necesidades y menos complicaciones lingüísticas; por mucho, llega al reconocimiento de que no posee el don de la palabra, como el diputado, aunque, igual que éste, puede convertirse en merolico.

El emisor erudito, en general, finca en la lengua la esperanza de su prosperidad y, cuando ésta no florece en él correctamente, busca a otro erudito en lengua para que lo auxilie.

El emisor erudito a la violeta no da a conocer su humillación por las que otros llaman imperfecciones suyas, pero la crítica lo puede hacer sensible al cambio.

\footnotetext{
12 Cic., Or., 24-25: Omnes enim qui probari volunt voluntatem eorum qui audiunt intuentur ad eamque et ad eorum arbitrium et nutum totos se fingunt et accommodant. Itaque Caria et Phrygia et Mysia, quod minime politae minimeque elegantes sunt, asciverunt aptum suis auribus opimum quoddam et tamquam adipatae dictionis genus, quod eorum vicini non ita lato interiecto mari Rhodii numquam probaverunt Graecia autem multo minus, Athenienses vero funditus repudiaverunt; quorum semper fuit prudens sincerumque iudicium, nihil ut possent nisi incorruptum audire et elegans. Eorum religioni cum serviret orator, nullum verbum insolens, nullum odiosum ponere audebat.

${ }^{13}$ Cic., Or., 36: In picturis alios horrida, inculta, abdita et opaca, contra alios nitida, laeta, conlustrata delectant.
} 
El emisor pseudoerudito es el que mayores fuentes de trabajo ha ocasionado, por ejemplo, para profesores, correctores y pseudocorrectores de escritos ajenos, quienes también, en su función emisora de enseñanza o de corrección, se dividen en las cinco clases susodichas.

El emisor engreído es no solamente el ejemplo para todos los otros, sino la fuente del placer que genera la palabra. Así, por ejemplo, de Julio Cortázar podemos aprender a describir, de este modo:

J. Ese día las redes se dibujaban precisas en la arena, y Marini hubiera jurado que el punto negro a la izquierda, al borde del mar, era un pescador que debía estar mirando el avión. ${ }^{14}$

De José Emilio Pacheco, a deshacer intrigas:

K. imbéciles, siquiera pónganse de acuerdo antes de seguir diciendo pendejadas en un lenguaje que ni ustedes mismos entienden. ${ }^{15}$

De Augusto Monterroso, a ironizar:

L. Cada vez que aparecían ovejas negras eran rápidamente pasadas por las armas para que las futuras generaciones de ovejas comunes y corrientes pudieran ejercitarse también en la escultura. ${ }^{16}$

De Julio Torri, a reflexionar:

${ }^{14}$ Julio Cortázar, La isla a medio día, Norma, 1991, p. 99.

${ }^{15}$ José Emilio Pacheco, Las batallas en el desierto, IX: Inglés obligatorio.

${ }^{16}$ Augusto Monterroso, La oveja negra. 
M. Y para que no sufriera mancilla ninguno de los linajes... mandó el virrey que retrocedieran las carrozas al mismo tiempo. ${ }^{17}$

De Juan de Dios Peza, la ternura:

N. Sueña el niño con armas y caballo, la niña con velar junto a la cuna. ${ }^{18}$

Y todos los engreídos juntos nos enseñan la claridad y la corrección del lenguaje, cualidades que se basan en el amor a las palabras, dicho de otro modo, en la filología. Esto es, nos enseñan qué decir, en qué lugar, de qué modo y a qué receptor: el decoro de la palabra, lo que es conveniente. En fin, nos enseñan lo que nos podría llevar a comunicarnos más efectivamente o, al menos, a cometer cada vez menos errores en el discurso, el cotidiano o el preparado; en la poesía y aun en la vida misma. Lo cual no es sino la más grande exhortación para todo hablante derivada del precepto ciceroniano de estudiar filosofía, derecho, historia y especialmente literatura, fuente de la perfecta elocuencia, ${ }^{19}$ cuyo correcto cumplimiento haría, indudablemente, hombres superiores.

17 Julio Torri, Fantasías mexicanas.

18 Juan de Dios Peza, Fusiles y muñecas.

${ }^{19}$ Cic., Brut., 322: nemo erat qui videretur exquisitius quam volgus hominum studuisse litteris, quibus fons perfectae eloquentiae continetur; nemo qui philosophiam complexus esset matrem omnium bene factorum beneque dictorum; nemo qui ius civile didicisset rem ad privatas causas et ad oratoris prudentiam maxume necessariam; nemo qui memoriam rerum Romanarum teneret, ex qua, si quando opus esset, ab inferis locupletissimos testes excitaret. 